\title{
Arbor
}

\section{Los museos de historia natural en el siglo XIX: templos, laboratorios y teatros de la naturaleza*}

Leoncio López-Ocón Cabrera

Arbor CLXIII, 643-644 (Julio-Agosto 1999), 409-423 pp.

Se explica en este texto cómo y por qué los museos de historia natural se transformaron en "catedrales de la ciencia" durante el siglo XIX. Se plantea que esos lugares de la ciencia interesaron y fascinaron a expertos y profanos porque durante ese tiempo histórico lograron conciliar una triple función cognoscitiva y comunicativa: la de ser templos, laboratorios y teatros de la naturaleza.

$\left.1^{a}\right)$ como depósito de las colecciones del mundo natural se convirtieron en un lugar de acumulación de tesoros y de adhesión a valores politicos y científicos.

$2^{a}$ ) como ámbito de trabajo de los naturalistas que revelaban las claves del orden natural se transformaron en centros de investigaciones para ordenar y descifrar la naturaleza

$3^{a}$ ) como escenarios en los que se mostraban las maravillas de la naturaleza se autoconcibieron como una especie de gran teatro en el que se representaban lecciones de cosas del mundo natural a modo de un libro abierto.

* Este trabajo se realizó hace ya un tiempo, en 1994, cuando tuve una beca posdoctoral del Ministerio de Educación y Ciencia en el Centre de Recherche en Histoire des Sciences et des Techniques del Museo de La Villette de Paris. Los ánimos dados por varios colegas, como Antonio Lafuente y Eulalia Moreno, me han animado a darlo a la luz. 


\section{Leoncio López-Ocón Cabrera}

Escaparates de la riqueza y de la variedad de los componentes de los tres reinos de la naturaleza, centros de investigación y de procesamiento de la información almacenada en grandes colecciones de objetos naturales, lugares de culto destinados a estimular entre sabios e ignorantes el amor a la belleza y la afición al conocimiento de las maravillas de la $\mathrm{Na}$ turaleza, esas son algunas de las principales funciones que desempeñaron los museos de ciencias naturales que proliferaron por todos los rincones del planeta a lo largo del siglo XIX.

Sus orígenes se encuentran en las "Kunst und Wunderkammern" de la sociedad de corte ${ }^{1}$. Esas cámaras de maravillas desempeñaron un notable papel en la tecnología del poder de la Europa absolutista pues en ellas se reunían las obras de arte para mostrar la autoridad de los representantes políticos del antiguo régimen y las exhibiciones de sus contenidos a los invitados elegidos eran concebidas para reforzar el poder del príncipe ${ }^{2}$.

Pero esas instituciones no han de ser vistas exclusivamente como un aspecto de esa tecnología del poder. Son el resultado asimismo de un doble movimiento cultural. Parte de su raíces se hunden en la cultura de la curiosidad desplegada por los europeos en los albores de la era moderna ${ }^{3}$, que impulsó la creación de centenares de esas "Kunst und Wunderkammer" por toda Europa durante los siglos XVI y $\mathrm{XVII}^{4}$. Y los gabinetes de curiosidades del ámbito cultural anglosajón son a su vez causa y efecto de la nueva sensibilidad creada por la filosofía experimental baconiana cuyos impulsos estéticos, sociales, económicos e intelectuales estimularon la formación de colecciones y su concepción como instrumentos de popularización de la ciencia ${ }^{5}$.

Los museos de historia natural surgieron en efecto cuando los coleccionistas privados empezaron a abrir al público a partir del siglo XVII sus gabinetes de curiosidades. Las razones de esa apertura fueron diversas: afán de exhibir riquezas, preocupaciones pedagógicas, espíritu de emulación de la aristocracia, interés en el desarrollo de colecciones de referencia para médicos y farmaceúticos se entrecruzaron en esas motivaciones. Muchos de esos gabinetes se organizaron para exponer y evocar los prodigios, la variedad y las riquezas de la naturaleza o para presentar un modelo reducido del universo, un microcosmos, haciéndolo visible en su totalidad.

En esas cámaras de maravillas predominó en un principio el interés por las cosas raras; se atesoraron "semióforos", es decir objetos a los que se dio importancia no por su valor de uso sino a causa de su significación como representantes del mundo invisible, es decir de países exóticos, de sociedades diferentes, de climas extraños ${ }^{6}$.

Luego a mediados del siglo XVIII ese interés por las cosas raras, por la acumulación de "semióforos", de cosas y objetos que representaban lo "invisible", fue sustituido por el entusiasmo por la historia natural. Se 


\section{Los museos de historia natural en el siglo XIX}

modificó entonces la fisionomía de las colecciones que se custodiaban en esos lugares de culto que eran las "cámaras de maravillas", y surgió el gabinete de historia natural como un "compendio" de toda la naturaleza, orientado sobre todo a dar respuesta a interrogantes científicos, relacionados fundamentalmente con los problemas de la clasificación de los seres naturales. Ciertamente tales gabinetes de la segunda mitad del siglo XVIII estaban abiertos a los amantes y curiosos de las ciencias naturales, pero tal apertura era restringida ${ }^{7}$. Solo con el advenimiento de la Revolución francesa se convirtieron en verdaderas instituciones públicas poniendo sus colecciones al alcance de todos y diseñando una política de popularización de los conocimientos que se generaban en ellos. El 10 de junio de 1793 la Convención transformó el "Jardin des Plantes" en "Muséum national d'histoire naturelle" para crear una especie de "metrópoli de todas las ciencias útiles a la agricultura, al comercio y a las artes" ${ }^{\prime \prime}$. Los profesores del Museo, como Lamarck o Cuvier, emprendieron entonces una ambiciosa obra de vulgarización en la que se combinaban la investigación rigurosa, las visitas organizadas de curiosos y aficionados, y los cursos populares.

Si bien esas campañas de alfabetización científica fueron objeto de sá-

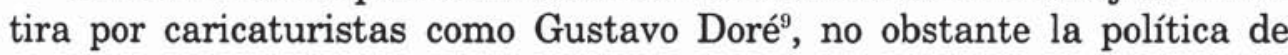
puertas abiertas de las instituciones creadas por los revolucionarios franceses y su afán de hacer la ciencia accesible a todos ejerció una profunda influencia a lo largo de todo el siglo XIX y favoreció la eclosión a lo largo de esa centuria de un movimiento de creación de museos de historia natural que afectó a todos los rincones del planeta, desde las colonias británicas en Oceanía hasta las nuevos estados independientes de la América lati$\mathrm{na}^{10}$. Muchos de esos museos, sobre todo en los Estados Unidos, fueron promovidos y alentados por un pujante movimiento de naturalistas "amateurs", que jugó un importante papel en el desenvolvimiento de tales instituciones científicas ${ }^{11}$. Esas catedrales de la ciencia interesaron y fascinaron durante el siglo XIX a expertos y profanos porque durante ese tiempo lograron conciliar su triple función: la de depósito de las colecciones del mundo natural, la de ámbito de trabajo de los naturalistas que descifran las claves del orden natural y la de escenario en el que se muestra de manera tridimensional las maravillas de la complejidad de la naturaleza.

\section{El museo como templo: un lugar de acumulación de tesoros y de ahesión a valores políticos y científicos}

Los museos de historia natural emergen en el siglo XIX como los lugares donde se rinde culto profano a la nueva religión de la ciencia. El 


\section{Leoncio López-Ocón Cabrera}

hecho de que esos museos tomen el relevo de iglesias y templos como lugares en los que los miembros de una sociedad puedan comulgar en la celebración de un mismo culto explica las profundas analogías de los museos y de los templos en su ordenación espacial, en la manera en la que exponen sus "tesoros", y en el proceso de formación de las colecciones que atesoran.

$\mathrm{Si}$ en la antigüedad romana el templo era el espacio delimitado, orientado y consagrado por los augures para efectuar un acto sagrado 0 llevar a cabo sus observaciones, en el siglo XIX el museo era el espacio cerrado en el que los científicos se dedicaron a cultivar el conocimiento mediante el estudio y análisis de las colecciones que se almacenaban en ellos como verdaderos tesoros de la naturaleza. El alzado de los mismos museos, como por ejemplo, el de la ciudad argentina de La Plata, que se construyó a fines de la década de 1880 , parecen inspirarse en la arquitectura de los templos clásicos greco-latinos ${ }^{12}$. La misma organización del espacio interior de los museos con su espacio diferenciado para el público y para las colecciones ${ }^{13}$ guarda asimismo semejanzas con el diseño de la organización espacial de los templos de todas las religiones en el que se establece una nítida separación entre los ámbitos dedicados a los fieles y a los sacerdotes. La escenografía tiene asismismo rasgos comunes. En el musec así como en el templo las condiciones de presentación de los objetos son similares: un juego de luces envuelve a las piezas más veneradas, y gracias a la creación de una atmósfera que incita a la admiración el espectador contempla con deleite las piezas exhibidas. En los templos antiguos se reunían y exponían las ofrendas para ser admiradas por los peregrinos. Esas ofrendas procedían, en su mayor parte, de donaciones de los fieles, que expresaban de esa manera su adhesión al panteón del santuario con el que se vinculaban. En el desarrollo de las colecciones de los museos de historia natural desempeñan asimismo un notable papel los dones realizados por sabios o profanos, que manifiestan de esa manera un afecto a la institución y una identificación con sus funciones sociales y culturales. Es conocido el hecho de que en el mundo anglosajón han sido numerosos los mecenas que gracias a sus legados han permitido el enriquecimiento de las colecciones de los museos o incluso su propia creación como fue el caso de la importante donación que hizo en 1675 Elías Ashmole de sus colecciones a la Universidad de Oxford, origen de la creación en 1683 del Ashmolean Museum, considerado como el primer museo de Historia natural de carácter pedagógico ${ }^{14}$. Pero en el ámbito cultural latino tampoco ha sido despreciable ese fenómeno. El museo de historia natural de la universidad de Padua surgió de las colecciones que en 1733 donó el hijo del célebre naturalista Antonio Vallisnieri ${ }^{15}$. Y en la comunidad iberoameri- 


\section{Los museos de historia natural en el siglo XIX}

cana las pruebas abundan de la existencia de ese mecenazgo. El agustino Barreiro en su historia del Museo Nacional de Ciencias Naturales de Madrid, escrita hacia 1935 a modo de unos Anales, no cesa de ofrecer puntual información de las paulatinas donaciones que permitieron incrementar incesantemente sus colecciones hasta convertirlo a principios de este siglo, bajo la dirección de Ignacio Bolívar, en uno de los más importantes del mundo ${ }^{16}$. El museo de Historia Natural de la ciudad argentina de La Plata, creado a fines de 1884, y situado asimismo en primera línea del movimiento museístico mundial a fines del siglo XIX está asociado a las donaciones que hizo su fundador Francisco P. Moreno de sus importantes colecciones paleontológicas y de su propia biblioteca de más de 2.000 volúmenes ${ }^{17}$. El más modesto Museo de Historia Natural de la ciudad chilena de Valparaiso, creado y sostenido en la década de 1890 gracias a la iniciativa y cuidados de Carlos E. Porter, estuvo apoyado por toda una red de amigos de la institución, pertenecientes en su mayor parte a la élite local de ese puerto del Pacífico sur, que ritualmente efectuaban sus donaciones ${ }^{18}$.

Todas las ofrendas de esa miriada de filántropos a esos templos de la ciencia ¿qué significado tienen?.

En primer lugar, expresan un interés por lo propio, un sentimiento de pertenencia local. Gran parte de esas donaciones desean contribuir a la perfección del inventario de los recursos del propio territorio y a hacer posible un uso racional de ellos. Las ofrendas de esos "caballeros andantes" que son los naturalistas de los tiempos contemporáneos crean entonces un patrimonio que se hereda, se gestiona y se transmite, que habla del pasado y se vive en el presente y en el futuro. Es ese patrimonio el que es objeto de culto por la patria o por la nación.

En segundo lugar, manifiestan el afán de los ciudadanos de participar en la vida de las instituciones científicas. Como ha subrayado el historiador franco-polaco Pomian hay un vínculo entre ciudadanía y filantropía, el cual ha de ser contemplado como la expresión de un afecto a la patria a la que se quiere agradecer e ilustrar facilitando el libre acceso a las colecciones del público. De esta manera cuanto mayor es la participación de los individuos en los asuntos públicos, mayor es la propensión de estos a poner sus bienes al servicio de la colectividad ${ }^{19}$. Así, por ejemplo, el ayudante del Museo de Ciencias Naturales de Madrid Marcos Jiménez de la Espada donó en 1881 al Museo Arqueológico Nacional parte de la colección etnográfica que formó cuando recorrió entre 1862 y 1865 el Nuevo Mundo como integrante de la Comisión científica del Pacífico tras haber participado activamente en la vida pública española como organizador del importante congreso de Americanistas que se celebró en Madrid en ese año ${ }^{20}$. 


\section{Leoncio López-Ocón Cabrera}

En tercer lugar, muestran la voluntad de cooperar en el trabajo científico que se desarrolla en los museos de historia natural. A través de sus ofrendas los donantes desean contribuir a crear una común interpretación y representación del mundo natural y pretenden que la información que reúnen sea inmortal manteniendo su integridad a través del tiempo, del espacio y de las contingencias locales. Los donantes, en suma, aparecen como aliados fundamentales de la labor que desempeñan los científicos, los nuevos sacerdotes de esos templos del saber.

\section{El museo como laboratorio: un centro de investigaciones para or- denar y descifrar la naturaleza y un lugar de comunicaciones científicas}

Esos templos-museos fueron, en efecto, una de las sedes de las prácticas científicas llevadas a cabo por numerosos naturalistas entre mediados del siglo XVIII y principios del siglo XX. Un símbolo de esa tradición de investigación son los lugares de los museos en los que un rótulo advierte que no pueden ser transitados por el público porque están reservados al estudio de las colecciones. En esos laboratorios, en esos espacios reservados a la investigación, se efectuaron múltiples tareas: se ordenaron y clasificaron los elementos del "arca de Noé", se descifraron las claves del funcionamiento de la naturaleza y se elaboraron métodos y reglas normalizadas para preservar y coordinar la múltiple información proporcionada por los objetos coleccionados que se custodiaban en su seno.

Si en un principio los naturalistas que trabajaron en esos laboratorios centraron su labor en estudios clasificatorios y morfológicos, posteriormente desplazaron el centro de su interés al análisis de los patrones y procesos que sufren los seres vivos como partes integrantes del sistema natural. Con ese cambio de enfoque se diversificaron los métodos y las prácticas de trabajo. Los primeros métodos de la historia natural, predominantemente observacionales y comparativos, se fueron refinando y completando con métodos experimentales y técnicas cuantitativas que caracterizarían a la ciencia biológica que emergió en el siglo XIX, permitiendo de esa manera centrar la atención en la investigación de problemas cada vez más especializa$\operatorname{dos}^{21}$.

En el "Muséum d'histoire naturelle" de Paris se desplegó, por ejemplo, entre 1795 y 1815 un poderoso movimiento de investigaciones que condujo a la determinación exacta de la mayor parte de las clases zoológicas ${ }^{22}$. En esa tarea sobresalió Georges Cuvier, profesor en el Museo desde 1795 


\section{Los museos de historia natural en el siglo XIX}

de la Anatomía de los animales. Sus disecciones anatómicas y el examen consiguiente de la comparación de la organización interna de los animales, han sido consideradas como el factor técnico o -práctico- que permitió hacer progresos definitivos en la delimitación de las clases taxonómicas. Sus investigaciones en torno a los principios de clasificación del mundo animal le permitieron realizar notables contribuciones a la Anatomía comparada y a la Paleontología ${ }^{23}$.

Décadas más tarde el frente de investigaciones que se llevaba a cabo en esos laboratorios se desplazó hacia el conocimiento de las funciones de los seres vivos. Así en el museo de Rouen, fundado en 1828, se instaló en 1840 un laboratorio en el que su primer director Félix-Arquímedes Pouchet realizó entre 1842 y 1847 una serie de investigaciones sobre la ovulación espontánea y la fecundación de mamíferos y de la especie humana, y entre 1858 y 1867 sobre el origen de los microorganismos que le conducirán al debate con Pasteur sobre la denominada "generación espontánea”, en el que resultó perdedor ${ }^{24}$.

Finalmente en las décadas finales del siglo XIX y primeras del siglo XX las investigaciones desplegadas en los laboratorios de los museos de historia natural se vieron afectadas por la potencia del paradigma darwiniano. Emergió entonces la ecología como una subdisciplina diferente a la sistemática, a la morfología y a la genética que hasta entonces habían dominado el panorama de las investigaciones biológicas. Los ecólogos intentaron resolver problemas relacionados bien con la evolución, adaptación y la selección natural de los seres vivos, o con la biogeografía para estudiar la distribución y abundancia de los organismos, o con la fisiología para evaluar efectos de los factores físicos (calor, luz, suelo, humedad) en los ciclos vitales de las especies. Para llevar adelante ese programa los ecólogos aplicaron nuevos métodos de cuantificación y análisis y el uso de indicadores biológicos ${ }^{25}$. Uno de los laboratorios en los que se desarrolló un plan de trabajo de esa índole fue el "Museum of Vertebrate Zoology" fundado en Berkeley en 1908 y cuyo primer director, Joseph Grinnell, creador del concepto de "nicho", realizó importantes contribuciones al estudio de la distribución geográfica, de la ecología y la evolución de aves y mamíferos de California ${ }^{26}$.

Asimismo todos esos museos-laboratorios actuaron como grandes centros de procesamiento de la información proporcionada por los diversos actores que participaron en su funcionamiento tales como los naturalistas amateurs y los científicos profesionales, los filántropos o mecenas, los administradores, los conservadores y el público ${ }^{27}$.

Se generó en su seno un permanente esfuerzo para encontrar respuestas a los problemas de afrontar la complejidad, preservación y coor- 
dinación de la múltiple información proporcionada por los objetos colectados que se custodiaban en sus depósitos.

Los naturalistas profesionales centraron su atención en la preparación de métodos y en el desarrollo de reglas para normalizar los procedimientos de recolección y preservación de ejemplares, y de elaboración de etiquetas y de notas de campo para salvaguardar la información. Los ejemplares, en efecto, han de ser preservados de una manera normalizada para que la información específica pueda ser recuperada más tarde al almacenarse en el museo. Esos métodos habían de ser rigurosos y sencillos, pues debían usarse por amateurs que carecían de conocimientos teóricos, y al mismo tiempo tenían que conseguir que la información obtenida por los amateurs pudiese ser analizada por los profesionales. Generalmente el profesional convencía al amateur para que se adhiriese a sus convenciones, por ejemplo para que especificase claramente el habitat y el tiempo de la captura de un ejemplar en un cuaderno normalizado. Cada uno de esos protocolos puede ser visto por tanto como un registro de un proceso de reconciliación entre la ciencia académica y la ciencia popular.

La adopción y propagación de esos métodos y técnicas normalizadas tuvo diversos efectos en el ámbito de la comunicación de los actores que participaban en la vida del museo. Permitió la movilización de redes de recolectores de objetos, de científicos cooperantes y de administradores para asegurar la integridad de la información recogida para su archivo e investigación. Proporcionó el uso de una "lengua franca", entre amateurs y profesionales. Y favoreció que los amateurs hiciesen sustanciales contribuciones a la conservación y al conocimiento científico pues sus objetos y cuadernos normalizados proporcionaron una información consistente a las generaciones futuras o a los investigadores distantes. De esa manera las redes de comunicación científicas generadas en el museo, como en cualquier otro laboratorio, pudieron desplazarse por el tiempo y por el espacio ${ }^{28}$.

\section{El museo como teatro: un libro abierto y un escenario al alcance de todos}

Pero esas "catedrales de la ciencia" del siglo XIX fueron ante todo privilegiados ámbitos de comunicación científica con el "gran" público a través de procedimientos didácticos y museográficos, tendentes a hacer accesibles a la comprensión del mayor número posible de visitantes los secretos de la naturaleza. El museo fue concebido como un gran teatro, 


\section{Los museos de historia natural en el siglo XIX}

como un locus donde se exhiben y representan verdades eternas. En él se explicaban y representaban las claves del libro de la naturaleza con la ayuda de diversos instrumentos. Se entremezclaban diversas artes y técnicas representativas de manera análoga a lo que sucedía en una de las manifestaciones artísticas características del siglo XIX: la ópera.

El uso de la enseñanza para difundir conocimientos y popularizar las ciencias naturales fue uno de los objetivos fundamentales de muchos de los museos de historia natural decimonónicos y de sus instituciones hermanas los jardines botánicos. Como manifestara Georges Pennetier, - director del museo de Historia Natural de la ciudad francesa de Rouen entre 1873 y 1923 -, un museo era no sólo una reunión de objetos clasificados científicamente, sino también un lugar de enseñanza popular, "une leçon de choses", un libro abierto a todos ${ }^{29}$. De manera análoga, ya en 1822, el gran botánico Augustin-Pyramus de Candolle comentaba que el jardín botánico era "une espèce de livre vivant que chacun consulte avec fruit" y abogaba para que estuviesen abiertos al público fuera de las horas en las que se impartían las lecciones de botánica no solo por razones pragmáticas - i la presencia del público estimularía las actividades del personal! - sino por razones pedagógicas: se trataba de que esos lugares de desarrollo de la cultura científica estimulasen las ganas de saber, difundiesen conocimientos y asegurasen a las instituciones científicas el favor de la opinión pública ${ }^{30}$.

Muchos museos de historia natural del siglo XIX se concibieron por tanto como una escuela permanente de divulgación científica y la práctica de impartir cursos abiertos al gran público se generalizó. Quizás los más famosos de esos cursos fueron los que impartieron a principios de esa centuria, en su época de mayor esplendor, los profesores del Museo de Historia Natural de París: los botánicos Desfontaines y Thouin, los mineralogistas Laugier, Vauquelin y Haüy y los zoólogos Lamarck, Geoffroy Saint-Hilaire, Duméril y Georges Cuvier. Pero también se impartieron en los museos provinciales franceses como el de la ciudad portuaria de Nantes, donde sus conservadores, a lo largo de la segunda mitad de siglo, fomentaron la enseñanza de la geología y procuraron unir los conocimientos teóricos a los prácticos con la organización de excursiones sobre el terreno ${ }^{31}$.

Algunos de esos naturalistas alejados de París desarrollaron una importante labor divulgativa como el fundador del Gabinete de Historia Natural de Rouen, el ya mencionado Félix-Arquímedes Pouchet, para quien el verdadero sabio era el que conciliaba la investigación con la difusión científica como explicó detalladamente en el prefacio de L'Univers, un importante libro divulgativo, que conoció tres ediciones. Desde su museo 


\section{Leoncio López-Ocón Cabrera}

Pouchet impulsó la propagación de las ciencias naturales y cuidó al máximo los elementos didácticos de los cursos que impartió a partir de la década de 1830, auspiciados por el municipio. En ellos alternaba lecciones de carácter elemental con otras en las que presentaba un estado de la cuestión de diversos problemas científicos de la época o exponía sus investigaciones. Elaboraba con cuidado el texto y la dicción de sus conferencias, las ilustraba con objetos y animales que se exponían en el Museo y con dibujos elaborados por él mismo, usó además para ilustrar sus disertaciones innovaciones técnicas como un microscopio solar - que además de servir para investigaciones micrográficas, permitía la proyección engrandecida de micro-organismos vivos -, y recurrió al humor y a la imaginación en sus explicaciones como fue el caso de sus lecciones sobre el "cocodrilo". Esos cursos gratuitos se anunciaban a través de carteles y por medio de la prensa, y atraían regularmente al anfiteatro adjunto al museo, a unas 150 o 200 personas, estudiantes y burgueses ilustrados, que participaban en la animación cultural de la ciudad. Si en el verano los cursos que se impartían eran de botánica, el invierno se dedicaba a la enseñanza de la zoología, la fisiología y la geología $a^{32}$.

Esos museos de historia natural procuraron pues no ser un simple lugar de paseo en el que se ejercita la curiosidad. Intentaron más bien convertirse en teatros de educación científica para el visitante autónomo. Para ello se usaron diversos procedimientos. Se editaron cuidadas guías para orientar a los visitantes. Así en la época bajoisabelina y del Sexenio democrático, etapa en las que hubo un notable esfuerzo de promoción de la cultura científica en la sociedad española, los naturalistas Graells y Solano editaron sendas guías del Jardín Botánico y del Gabinete de Historia Natural de Madrid ${ }^{33}$. Los responsables de los museos asimismo se esforzaron en mejorar la exposición de los objetos desde un punto de vista pedagógico mediante la elaboración de textos, etiquetas y mapas en los que se efectuaban comentarios explicativos de manera didáctica. Pero sobretodo concedieron una especial importancia a la puesta en escena de los objetos y a su presentación estética. Hubo en muchos de esos museos una voluntad de escoger temas de representación próximos a las vivencias del visitante medio, como podían ser la zoología agrícola o el medio marino local, y existió en ellos además un afán de difundir los saberes científicos mediante una presentación atractiva y sugerente de los objetos. En el caso del mundo animal se optó por el uso de los dioramas en los que se presentaban los animales en su habitat habitual. Con ese recurso escenográfico se buscaba estimular las impresiones visuales del espectador para transmitirle enseñanzas por los ojos. Esas vistas panorá- 


\section{Los museos de historia natural en el siglo XIX}

micas, que se propagaron solo a fines del siglo XIX, lograron su objetivo de entretener al público. Al mostrar a los animales en acción, desplegando sus costumbres en su entorno natural, se hizo más atractivo el espectáculo de la naturaleza para el visitante del museo. Con ese simulacro de vida el museo dejó de ser triste. En aquellas galerías en las que se introdujeron dioramas la afluencia de público creció considerablemente ${ }^{34}$.

Durante la etapa dorada de esas instituciones, algunos de sus directores, por sus cualidades científicas y por los apoyos que recibieron de los vectores mediáticos, obtuvieron una estima cultural como sucedió en la relación que se estableció entre el historiador Jules Michelet con el museo de historia natural de Rouen y con su director Pouchet, que le permitió redactar su obra L'Oiseau (1856, reeditada en 1894) y sus fantasías de historia natural ${ }^{35}$.

Pero al adentrarse el siglo XX los museos de historia natural empezaron a convertirse en instituciones obsoletas y perdieron el favor del público. No pudieron mantener unidas las tres funciones que le habían dado vigor en el siglo XIX: las de ser depósito de colecciones, laboratorios de investigación y lugar de enseñanza pública. El desarrollo de la biología imposibilita al museo exhibir toda la variedad de la cadena de los seres vivos. Pero como perdurase su afán de mostrar de manera exhaustiva esa impresionante variedad sus salas y vitrinas se abarrotaron de objetos y el paseante recibía entonces una compleja sensación, hecha de confusión, de fatiga e indiferencia ${ }^{36}$. Y su organización siguió orientada fundamentalmente por la sistemática. Aunque se reunieron colecciones de carácter regional, y aunque se manifestaron en ellos paulatinamente preocupaciones sobre el habitat y el medio ambiente, prefigurando de esa manera las actuales presentaciones "ecológicas", los métodos de clasificación siguieron siendo esencialmente los de la clasificación animal. Los fósiles se exponían en las salas de geología, pero clases y especies se sucedían en las salas de zoología en un orden que parecía inmutable. El texto fundacional del darwinismo Del origen de las especies apareció en 1859 , pero la teoría de la evolución estuvo sometida a una viva controversia y sólo fue realmente aceptada por la comunidad científica internacional a fines de ese siglo XIX. Además, las dificultades para reestructurar las colecciones y exponer los objetos para "hacer ver" la evolución de los seres vivos son importantes ${ }^{37}$. Hay que esperar pues ya al siglo XX, bien entrado, para que se conciban presentaciones "evolucionistas" de envergadura como el proyecto de la Galería de la Evolución del Museo de Historia Natural de Paris, recientemente abierto al gran público. 


\section{Leoncio López-Ocón Cabrera}

420

\section{Notas}

${ }^{1}$ El clásico estudio de ese tipo de sociedad es el de Norbert Elias, The Court Society (Oxford: Blackwell, 1983).

${ }^{2}$ Ver sobre esta cuestion Eilean Hooper-Greenhill, Museums and the Shaping of Knowledge (London: Routledge, 1992), p. 103 y L. Seeling, "The Munich Kunstkammer" en O.Impey y A. MacGregor, eds., The Origins of Museums (Oxford, Oxford University Press, 1985), pp. 76-89, citados por S. Shaffer, "Spaces of Experiment n1 1. Courts, markets and perpetual motions in 1721". Paper presentado al Seminario del CRHST de La Villette. Paris, 26 abril 1994, pp. 24-25

"ver "La culture de la curiosité" y "Les collections vénètes à l'époque de la curiositê" en Krzystof Pomian, Collectionneurs, amateurs et curieux. Paris, Venise: XVIe-XVIIIe siècle, (Paris, Editions Gallimard, 1987), 61-80, 81-142

4 ver Oliver Impey; Arthur MacGregor (editores), The Origins of Museums: The Cabinet of Curiosities in Sixteenth-and Seventeenth-Century Europe, (Oxford, Oxford University Press, 1985); El caso español es analizado en J.Miguel Morán y Fernando Checa, El coleccionismo en España. De la cámara de maravillas a la galería de pinturas, (Madrid, Cátedra, 1985).

"Ver a propósito de esta cuestión la excelente reseña de Lorraine J. Daston, "The Factual Sensibility", Isis, vol. 79, (1988), 452-67.

${ }^{6}$ Krzystof Pomian, "Entre l'invisible et le visible: la collection", en op. cit. (nota 3), p. 49.

'Así sucedía, por ejemplo, en los gabinetes franceses y españoles. Sobre los franceses ver: E. Lamy, Les Cabinets d'histoire naturelle en France au XVIIIè siècle et le Cabinet du Roi (1635-1793), (Paris, 1930) e Yves Laissus, "Les cabinets d'histoire naturelle" en R. Taton, dir: Enseignement et diffusion des sciences en France au XVIIIè siècle, (Paris, Hermann, 1986), pp. 659-712. Sobre el caso español ver $\mathrm{M}^{\mathrm{a}}$ Angeles Calatayud, Pedro Franco Dávila: primer director del Real gabinete de historia natural, (Madrid, CSIC, 1988).

${ }^{8}$ Roland Schaer, L'invention des musées, (Paris, Découvertes Gallimard, 1993), p. 58

"Ver "Cours d'anatomie comparée au Jardin des Plantes", grabado de Gustave Doré, Biblioteca Nacional de Paris, reproducido en R. Schaer, op. cit. (nota 8), p. 60.

${ }^{10}$ ver Susan Sheets-Pyenson, Cathedrals of Science. The Development of Colonial Natural History Museums during the Late Nineteenth Century, (Kingston \& Montreal, McGill-Queen's University Press, 1988). Sobre el caso australiano ver Sally Gregory Kohlstedt, "Australian Museums of Natural History: Public Priorities and Scientific Initiatives in the 19th Century", Historical Records of Australian Science 6 (1983): 1-29. Sobre el caso brasileño ver los trabajos de Maria-Margaret Lopes: "Contribuiçao à história dos museus de Geologia no Brasil”, en Margaret Lopes y Silvia Figueiroa (eds.), O Conhecimento Geológico na América Latina: Questoes de História e Teoria, (Campinas, Universidad Estadual-Instituto de Geociencias, 1990), pp. 47-60 y "Brazilian Museums of Natural History and International Exchanges in the Transition to the 20th Century", en Patrick Petitjean, Catherine Jami y Anne Marie Moulin, Science and Empires, (Dordrecht, Kluwer Academic Press, 1992), pp. 193-200. Para el caso colombiano ver Olga Restrepo Forero, "Naturalistas, saber y sociedad en Colombia", en Olga Restrepo, Luis Carlos Arboleda y Jesús Antonio Bejarano (eds.), Historia Natural y Ciencias Agropecuarias, (tomo III de Historia Social de la Ciencia en Colombia, Bogotá, Colciencias, 1993), pp. 131-153.

"Ver por ejemplo Sally Gregory Kohlstedt, "Curiosities and Cabinets: Natural History Museums and Education on the Antebellum Campus", Isis, vol. 79, (1988), 405-26 y "The Nineteenth-Century Amateur Tradition: The Case of the Boston Society of Natural 


\section{Los museos de historia natural en el siglo XIX}

History", en Gerald Holton y William Blanpied (eds.), Science and its Public, (Dordrecht, Holanda, D. Reidel), 1976, pp. 173-90.

${ }^{12}$ Richard Lydekker, "La Plata Museum" con fotografia en Natural Science 4 (1894): 1-21 citado y reproducida la fotografia en Susan Sheets-Pyenson, op. cit., (nota 10).

${ }^{13}$ Ver por ejemplo "W.H. Flower's Plan for the Arrangement of an Ideal Natural History Museum" en W.H. Flower, Essays on Museums and Other Subjects Connected with Natural History (London and New York: Macmillan \& Co. 1898), p. 50 citado y reproducido en Susan Sheets-Pyenson, op. cit. (nota 10), p. 7 figura 1.

"Y. Herreman, "De gabinetes a museos", Quipu, México 2 (3): 481-488, setiembre-diciembre 1985, p. 485. Sobre la formación y la historia de ese museo ver: Arthur MacGregor (editor), Tradescant's Rarities: Essays on the Foundation of the Ashmolean Museum, 1683; with a Catalogue of the Surviving Early Collections, (Oxford, Oxford University Press, 1983) y R.F. Ovenell, The Ashmolean Museum, 1683-1894, (Oxford, Oxford University Press, 1986).

${ }^{15}$ Ver K. Pomian, op. cit., (nota 3), pp. 123-125, 297.

${ }^{16}$ Agustín J. Barreiro, El Museo Nacional de Ciencias Naturales (1771-1935), (Madrid, Ed. Doce Calles, 1992).

${ }^{17}$ Susan Sheets-Pyenson, op. cit., (nota 10), pp. 88-89. Sobre ese Museo ver también Mario E. Teruggi, Museo de La Plata: 1888-1988, una centuria de honra, (Fundación Museo de la Plata Francisco Pascasio Moreno, 1988).

${ }^{18}$ Así en 190239 personas realizaron donaciones al Museo, que permitieron incrementar sobre todo sus colecciones de vertebrados y artrópodos. El origen geográfico de esos donantes fue el siguiente: no chilenos: La Habana 1 (S.C. Bañados), Paita 1 (F.D.L. Silva), Quito 1 (C.R.Tobar); chilenos: Coquimbo 1 (N.Valenzuela), Chillán 1 (J.M.Rivera), Caldera 2 (E. Gigoux, el jefe del faro), Quillota 2 (G.L. Leberton, F. Paulsen), Punta Arenas 2 (C. Plaza, H. Saunders), de la Marina de Chile 3 (Fed. T. Delfin, C.E. Fuenzalida, B. Wilson), Valparaíso 25 (M.A. Cabezas, A. Delfin, Demaria Hnos, L. Figueroa, S. Figueroa, Dr. E. Fraga, A. de la Fuente, E. Gillet, J. Hacker, A. Honorato, S. Martínez, V. Meneses, T. Moser, K. Newman, Luisa Opazo, L. Orellana, R. Otaegui, M. Prado, G.E. Ramírez, Miss Ried, M.C. Rivera, G. Rohweder, Delfina Silva, C.R. Urquieta, V. Varela. Ver El Mu. seo de historia natural de Valparaiso durante el año de 1902, memoria ...por el prof. Car. los E. Porter, (Valparaiso, imp. de Gillet, 1903).

${ }^{10} \mathrm{~K}$. Pomian, op. cit., (nota 3), pp. 302-303.

${ }^{20}$ ver Leoncio López-Ocón, De viajero naturalista a historiador: las actividades ame. ricanistas del científico español Marcos Jiménez de la Espada (1831-1898), (Madrid, Editorial de la Universidad Complutense, 1991, vol.I), p. 319.

${ }^{21}$ William Coleman, Biology in the Nineteenth Century: Problems of Form, Function and Transformation, (Cambridge, Cambridge University Press, 1977); Garland Allen, $\mathrm{Li}$ fe Science in the Twentieth Century, (Cambridge, Cambridge University Press, 1978); Keith Benson, "Concluding Remarks: American Natural History and Biology in the Nineteenth Century", American Zoologist, vol. 26, (1986), 381-384.

${ }^{22}$ Ver Henri Daudin, Cuvier et Lamarck. Les classes zoologiques et l'idée de série animale, (Paris, Félix Alcan, 1926-1927 (reed. PUF 1983). 2 vols). Sobre los orígenes del Museo ver también E.T. Hamy, "Les derniers jours du Jardin du Roi et la fondation du Muséum d'Histoire Naturelle", in Centenaire de la fondation du Muséum d'Histoire Na. turelle (Paris, 1893), pp. 1-162. Una panorámica general del desarrollo del Museo durante el siglo XIX en Camille Limoges, "The development of the Muséum d'Histoire Naturelle of Paris, c. 1800-1914" en Robert Fox y George Weisz (eds.), The organization of science 
and technology in France 1808-1914, (Cambridge, Cambridge University Press, 1980), pp. 211-240.

${ }^{23}$ Un interesante estudio biográfico de ese naturalista se encuentra en Dorinda Outram, Georges Cuvier: vocation, science and authority in post-revolutionary France, (Manchester, Manchester University Press, 1984).

" Recientemente ha analizado esa controversia Bruno Latour, "Pasteur y Pouchet: heterogénesis de la historia de las ciencias" en Michel Serres, dir., Historia de las Cien. cias, (Madrid, Cátedra, 1991), pp. 477-501. Un amplio estudio de las actividades científicas de ese adversario de Pasteur se encuentra en Maryline Cantor, Pouchet, savant et vul. garisateur. Musée et fecondité, (Paris, Z editions, 1994).

${ }^{25}$ Ver W.C. Allee, A.E. Emerson, O. Park, T. Park y K. Schmidt, Principles of Animal Ecology (Philadelphia \& London: W.B. Saunders, 1949); Sharon Kingsland, Modeling Nature: Episodes in the History of Population Ecology, (Chicago, The University of Chicago Press, 1985); R. McIntosh, The Background of Ecology, (Cambridge, Cambridge University Press, 1987).

${ }^{28}$ Susan Leigh Star y James R. Griesemer, 'Institutional Ecology, 'Translations' and Boundary Objects: Amateurs and Professionals in Berkeley's Museum of Vertebrate Zoology, 1907-39" en Social Studies of Science, vol. 19 (1989), pp. 387-420.

${ }^{27}$ ibid., pp. 393-397.

${ }^{28}$ ver Michel Callon, dir., La science et ses réseaux. Genèse et circulation des faits scientifiques, (Paris, La Découverte, 1989) y Daniel Parrochia, Philosophie des réseaux, (Paris, PUF, 1993), pp. 193-196.

${ }^{29}$ Discurso de Georges Pennetier tras la inauguración de nuevas salas en Petit Rouennais, 2 de setiembre de 1899, citado por M. Cantor, op. cit., (nota 24), p. 52.

${ }^{30}$ Decía en efecto: "Il faut donc qu'un jardin d'instruction soit toujours ouvert à tous ceux qui veulent étudier; il est même avantageux qu'il le soit à ceux qu'on pourroit croire n'y devoir rien apprendre: ils y prennent souvent le goût de l'étude; ils y puisent des connoissances incomplètes, il est vrai, mais exactes, qu'ils portent avec eux dans leurs voyages, dans leurs promenades, dans leurs vocations particulières. Cette liberalité, introduite dans les établissements de sciences, leur concilie l'intérêt du public entier, et n'est pas une des moindres causes des succès qu'elles ont obtenue dans ces derniers temps". A. P. de Candolle, "Jardin de botanique". En Frédéric Cuvier, Dictionnaire des sciences nature. lles 24: p. 174, (Strasbourg y Paris, 1822). Citado y comentado por Jean-Marc Drouin, "Une espèce de livre vivant: le rôle des jardins botaniques d'après Augustin-Pyramus de Candolle" en Saussurea, 24, 37, (1993), p. 42.

${ }^{31}$ Jean Dhombres, dir., Un Musée dans sa ville. Le muséum d'histoire naturelle. Sciences, Industries et Société à Nantes et dans sa région. XVIII ème - XX ème siècles (Nantes, Ouest Editions), 1990, pp. 306-315.

${ }^{32}$ ver $\mathrm{M}$. Cantor, op. cit. (nota 24$)$, pp. 53-57.

${ }^{33}$ ver Mariano de la Paz Graells, El Jardín Botánico y Zoológico de Madrid. Paseo instructivo y recreativo para todos dirigido por D.M.P.G, (Madrid, Imprenta de D. Alejandro Gómez Fuentenebro. Colegiata, 6, 1864). Es un folleto de 84 pp. Se vendía a 4 reales en la portería del Jardín Botánico; y José María Solano y Eulate, Guía del Gabine. te de Historia Natural, (Madrid, Imprenta de Gregorio Juste, 1871), 81. 99 pp. Solano fue también autor de unas Nociones de historia natural al alcance de los niños, 161, con grab. y una lámina en color, (Madrid, Imprenta de la Viuda de Aguado e hijos, 1869). Una visión general de ese interés por promover la cultura científico-técnica durante la última etapa del reinado isabelino y el Sexenio democrático en Leoncio López-Ocón, "El fomento de la educación y de la ciencia en la sociedad española del Sexenio democráti- 


\section{Los museos de historia natural en el siglo XIX}

co", Boletín de la Institución Libre de Enseñanza, ( $2^{\mathrm{a}}$ época), diciembre 1997, nº $28-29$, pp. $127-148$

${ }^{34}$ Así el museo de historia natural de la ciudad normanda de Rouen, en el que se introdujeron los dioramas en 1899 , el crecimiento de visitantes durante ese año fue espectacular: de 20 mil el año anterior a más de 38 mil durante ese año. Ver Maryline Cantor, "Un muséum de province au XIXè siècle: Félix-Archimède Pouchet et le Muséum d'histoire naturelle de Rouen", en La science pour tous, (Paris, Editions de la Réunion des musées nationaux, 1994, Les dossiers du Musée d'Orsay, n 52 ), p.50.

${ }^{35}$ ver E. Montegut, "Les fantaisies d'histoire naturelles par J. Michelet", Revue des Deux Mondes, 1861, n1 1, p. 719-741, citado por M. Cantor, op. cit., (nota 24), p.54.

${ }^{36}$ Louis Roule, "Les musées régionaux d'histoire naturelle et leur rôle dans l'enseig. nement public", Revue scientifique, 10 mars 1925.

${ }^{37}$ ver Michel Van-Praet: "Contradictions des musées d'histoire naturelle et évolution de leurs expositions", en Bernard Schiele, dir., Faire voir, faire savoir. La muséologie scientifique au présent, (Québec, Musée de la Civilisation, 1989), pp. 25-36 y "Diversité des centres de culture scientifique et spécifité des musées", en Aster, $\mathrm{n}^{\circ} 9,1989$, pp. 3-15 [n monográfico Les sciences hors de l'école]. 